\section{Keynote address at the opening ceremony for the centennial of the Pan American Health Organization}

\author{
David Satcher ${ }^{1}$
}

${ }^{1}$ Surgeon General of the United States of America. Remarks made at the opening ceremony for the centennial of the Pan American Health Organization, Washington, D.C., 7 January 2002.
Good morning. I bring you greetings from the Department of Health and Human Services [of the United States of America], especially the Office of the Surgeon General.

If September 11 and its aftermath represented mankind at its worstand it did-then today begins a celebration of mankind at its best. September 11 represents wanton destruction of human life without regard for innocence or person; PAHO [Pan American Health Organization] represents a commitment to enhance health across borders and in villages far beyond our own.

As the 16th Surgeon General, it's my pleasure to be a part of this celebration and to continue in the traditions of Surgeons General before me. Surgeon General Walter Wyman, the third Surgeon General, was present at PAHO's founding in 1902. He represented the continuation of an idea expressed by [United States] President Theodore Roosevelt in 1900: "A new century is a time for both celebration and reflection." Surgeon General Dr. Hugh S. Cumming was present to sign the Pan American Sanitary Code in 1924. Then there was Surgeon General Leonard Scheele, who led two delegations to the World Health Assembly and who was twice President of the World Health Organization. His famous statement, that "the world cannot exist half healthy and half sick," still rings true today. And finally, my Deputy Surgeon General, Ken Moritsugu, was there in Cuba representing the Secretary of Health and Human Services and me at the 75th anniversary of the signing of the Sanitary Code in 1999. So I am very delighted to be here today to celebrate this moment in PAHO's proud history.

As I look out over this audience, with all of its diversity, I cannot help but be reminded of the opportunity I had in Morocco a few years ago to meet with a group of African teenagers. It was during the Eighth International Conference on AIDS in Africa, and it was my first trip as Director of the Centers for Disease Control and Prevention [of the United States]. It was also the first time they had ever included teenagers in this conference, because they recognized that AIDS was increasingly becoming a problem of youth. When the teenagers found out the new Director of CDC was there, they insisted on meeting with me. I remember it clearly. On a Wednesday afternoon, they really drilled me with questions. They asked me when I thought we would have a vaccine for AIDS, and when we would have a cure. They asked if [the United States] was concerned about AIDS globally, or just among [persons in the United States]. As I listened to them, they reminded me so much of teenagers in this country [the United States]. So, I asked them a question too. I asked them for an explanation of why teenagers throughout the world seem to engage in high risk behavior. I talked about smoking rates in this country, and sexual behavior. I talked about violence and homicide and suicide. And I asked them, "Why do teenagers engage in such high risk behavior?" After looking at each other for a while, they responded by saying: "Dr. Satcher, have you heard that in Africa we say, 'It takes a village to raise a child'?" I thought for a minute and said, "Yes, I've heard that somewhere." They said: "Well, Dr. Satcher, if it takes a community or village to raise a child, where in the 1990s is our community? Where is the community that cares about children and supports each other's youth? Where is the community that protects the environment and assures that guns and drugs are not easily accessible to teenagers? Where is our community?" 
I struggled then with how to answer their question. Even today, I can still hear those teenagers and, indeed, even teenagers in this country, asking the same questions: "Where are the people who used to keep the schools safe? Where are the people who used to keep the communities safe so that you could walk and not worry about being shot? Where are the people who protect and care about our children, protect the environment, and keep the water and food safe? Where is our community?"

The question of where is our community is really a question about our commitment to public health. Public health also involves a commitment to our future health. It took years for me to come to a satisfactory response to that question. Today, it takes a global community to raise a child-and to protect a child against environmental hazards and terrorism.

PAHO's ability to stand strong after 100 years means you have mastered several key things. It means you have had a shared vision. I have come to realize just how important it is to have a shared vision. And I can only imagine what a challenge that is to negotiate among countries.

It also means you have had strong, committed leadership and a dedicated staff, which is evident even today.

And you have cross-border, cross-cultural caring. Dr. Ken Moritsugu said at the meeting in Cuba in 1999:

\begin{abstract}
We are all grateful to PAHO for its leadership in the development of Regional and Subregional strategies, the development of linkages for collaborative action, and the advocacy that is necessary to make the sum of our accomplishments greater than only individual national activities. PAHO has been, and continues to be, an effective catalyst for health. As countries, we are engaged in health activities as individual entities, but PAHO is our communications link, our guidance system, and our anchor.
\end{abstract}

These are the strengths that have brought PAHO to this place. This 100-year celebration represents the best of mankind, reaching across borders and caring about people and their health. It is one thing to have a vision, but another thing to care. That's the spirit of PAHO that has meant so much.

PAHO has made several major accomplishments over the last 100 years. PAHO has played a major role in the eradication of smallpox, the elimination of polio from the Western Hemisphere, and the near elimination of measles from the Americas. Then there's the Revolving Fund for Vaccine Procurement, which makes vaccines affordable for Member Countries through cooperative and joint negotiations with producers. Also, there's PAHO's Regional tobacco control effort and the 1992 report, Smoking and Health in the Americas, which the CDC developed in collaboration with PAHO. PAHO has also placed strong emphasis on prevention and early detection, with programs such as the one PAHO implemented for cervical cancer prevention in developing countries, an area where early identification and treatment of precancerous conditions can prevent the development of cervical cancer. There's also PAHO's growing leadership role in mental health, its role in health systems evaluation and measurement with its Member States, community-based violence prevention, and the model disaster relief efforts in Central America.

Clearly, PAHO has made major accomplishments in its first 100 years that will continue to improve the health of its Members States for decades to come.

When PAHO was organized in 1902, it was out of concern for communicable diseases, and PAHO's finest hours have been around the prevention of infectious diseases. 
Today, we face the global challenges of HIV/AIDS, one of history's most devastating diseases. This pandemic is changing the world and is a formidable threat not only to health but also to security, economies, education, and general quality of life. The Region of the Americas has not been spared. Today, there are nearly 38 million people in the world living with HIV/AIDS, and nearly 3 million of them are in the PAHO Region. There have been 23 million deaths globally. But here again, PAHO is in a position, using the vast offerings of technology and innovation, to lead the world.

Tobacco control remains a major challenge. Every Surgeon General since Luther Terry has been battling tobacco, and after nearly four decades, we have managed to bring down the number of smokers from about $43 \%$ in 1964 to about $25 \%$ today in the United States. I have produced three Surgeon General's reports on smoking and health during my short time in office: one on smoking and minorities, one on smoking cessation, and one on women and smoking. But we are concerned that as tobacco companies face severe losses in the markets in the United States, they are working to build up new markets in developing nations, where the current rates of smoking among women and among the young are minimal.

We are also concerned about violence, ranging from conflicts and wars and other disasters to bioterrorism, all of which threaten public health and which result in increasing refugee populations and orphans.

Safe food, blood, and water are also concerns.

Mental health is another major global concern. As Surgeon General, I have written widely on the subject and pointed out the global burden of mental disorders. We will not overcome this problem until we are willing to address the stigma and discrimination that continue to surround mental health disorders and that create barriers to intervention.

Economic uncertainty is a major concern today for the Southern Cone, but ultimately threatens all of us.

The elimination of racial and ethnic disparities has become an important area in the United States. When I was sworn in as Surgeon General, I adopted the elimination of racial and ethnic disparities in health as one of my top three priorities. And we were able to make it one of the two main goals of Healthy People 2010 [national health objectives for the United States].

But eliminating disparities in health presents PAHO with a serious challenge and is perhaps one of the most troubling areas to be concerned about. At the same time, it also represents a major opportunity. Major disparities exist within, between, and among the nations of the PAHO Region, and eliminating them must continue to be a focus of our activity for health. PAHO countries vary widely in their socioeconomic status and in the resources available and means to provide health care. But even within its more wealthy nations, major disparities exist. Socioeconomically, one in four children in Mexico lives in poverty; one in five children in the United States lives in poverty. Poverty promotes ill health. Eliminating disparities, especially among children, represents one of the most critical opportunities to improve human health. We believe that to the extent we address the health needs of the most vulnerable among us, we do the most to protect the health of the nation.

So, while we have come a long way in the last century, we still have a long way to go in the next. Let me offer some suggestions for the future.

We must do public health better. Quoting again from Deputy Surgeon General Ken Moritsugu's speech in 1999:

We have also come to understand that technological development alone will not lead to improved health. Our antibiotics do not treat health disparities, 
our vaccines do not prevent mothers without prenatal care from dying in childbirth, and our sophisticated medical equipment will not improve the access to basic health services for the poor. We are now more than ever challenged to understand what really will reduce the burden of disease and positively impact life expectancy. It is not health care alone, and it is not poverty reduction alone. It is likely a mix of policies, programs, and economic development that will be unique to each country in the Region.

We must take a multisectoral approach to health.

We must develop a global communications network.

Let me close where I began, with a discussion of community. My sense of community has changed greatly over the years. I grew up on a small farm just outside of Anniston, Alabama, where the community consisted of five neighboring farm families. We had no running water and no electricity, and obviously no television to give us a broader perspective of community. We were a close-knit community that helped each other through hard times. I can remember taking some of our crops or milk to other families when they did not have a good season, and vice versa. I can also remember on occasions when I ventured into town after having saved my allowance to purchase an ice cream cone, I was met with signs saying, "We do not serve [AfricanAmericans] here." That was my perspective of my community, and I thought that was the way of the world. But I have journeyed a long way from that very narrow sense of community. Today, my community is not only nationwide, as people call me "the nation's doctor," but I have friends and colleagues all around the world, from Australia and New Zealand, where we visited prior to developing the Surgeon General's Report on Mental Health, to South Africa, where I served on the health subcommittee of the U.S.-South Africa Binational Commission; to Russia, where we collaborated on tuberculosis; to Egypt, where we helped launch Healthy Egyptians; and to Uruguay, where we participated in the launch of Health Uruguay 2010. I was scheduled to leave on a flight to Uruguay on the evening of September 11, but obviously that trip had to be postponed and our participation rescheduled until a later date.

My point is this: Although I still have a small community and my family, my world has changed and my community has too. It has been redefined and expanded by technology and travel and communication and working relationships. It is this sense of global community, which we have found in public health, that must be the spirit by which we face all of our problems and opportunities.

PAHO is the oldest continuously operating international public health program in the world. And today marks the beginning of a great celebration. Yet, in the final analysis, it is not about the length of your existence but about how you have used time.

Let me leave you with this poem by an anonymous author:

\author{
God's Minute \\ I have only just a minute \\ Only 60 seconds in it \\ Forced upon me, can't refuse it \\ Didn't seek it, didn't choose it \\ But it's up to me to use it \\ I must suffer if I lose it \\ Give account if I abuse it \\ Just a tiny little minute \\ Yet eternity is in it.
}

